Thorax (1976), 31, 635.

\title{
Aspirated foreign bodies in the tracheobronchial tree: report of 250 cases
}

\author{
OSA M A A A D UL M A I D, ABDELMOMEN M. EBEID, \\ MOHA MED M. MOTAWEH, and IBRAHIM S. KLEIBO \\ Thoracic Surgical Unit and Anaesthesia Unit, Chest Diseases Hospital, Kuwait
}

\begin{abstract}
Abdulmajid, O. A., Ebeid, A. M., Motaweh, M. M., and Kleibo, I. S. (1976). Thorax, 31, 635-640. Aspirated foreign bodies in the tracheobronchial tree: report of 250 cases. During the last 14 years 250 patients with aspirated foreign bodies in the tracheobronchial tree were admitted to Kuwait Chest Diseases Hospital. Ninety-six per cent of the cases were under 10 years of age and $38 \%$ gave a clear history of foreign body inhalation. The rest were diagnosed either clinically, from the chest radiograph findings or because of unexplained pulmonary symptoms. In 247 cases, bronchoscopy under general anaesthesia was successful in removing the foreign bodies. In only three cases was bronchotomy needed. Seventy per cent of the foreign bodies were melon seeds. Asphyxia and cardiac arrest occurred in four cases during bronchoscopy but the patients were successfully resuscitated. In 10 cases a tracheostomy was done before bronchoscopy and the removal of the foreign body, while in five it was needed after the bronchoscopy. Fifteen patients developed late complications such as recurrent pneumonia or atelectasis of the lung. Early diagnosis and adequate treatment are essential to prevent pulmonary and cardiac complications and to avoid radical lung surgery.
\end{abstract}

\section{PATIENTS}

Of our 250 patients, 105 were under 2 years of age $(42 \%), 105$ were aged $2-6$ years $(42 \%)$, and 30 were $6-10$ years old $(12 \%)$. Only $4 \%$ of cases were above 10 years of age. One hundred and forty patients were female $(46 \%)$ and 110 were male $(44 \%)$. Of the foreign bodies, $70 \%$ were located in the right bronchial tree, $17 \%$ in the trachea, and only $13 \%$ in the left bronchial tree.

\section{DIAGNOSIS OF FOREIGN BODY INHALATION}

Early diagnosis depends on the following factors:

1. History of foreign body inhalation: 96 of the patients $(38 \%)$ gave a clear history of foreign body inhalation which was in itself diagnostic.

2. Clinical picture: 54 of the patients $(22 \%)$ presented with a history of an acute episode of choking and cough, which was highly suggestive of foreign body inhalation. The remaining 100 patients $(40 \%)$ presented with wheezing, cough, and dyspnoea which gave rise to a suspicion of foreign body inhalation.

3. Radiographic findings: $80 \%$ of patients showed normal radiographic findings and only $8 \%$ showed a definite foreign body shadow (Fig. 1). In eight cases the radiograph showed bilateral obstructive emphysema due to partial obstruction of the trachea, and in 12 cases it showed right or left lung emphysema due to partial obstruction of the bronchi (Fig. 2). Ten patients showed atelectasis of a lobe, of which seven were right lower lobes (Fig. 3) and three left lower lobes (Fig. 4).

\section{NATURE OF FOREIGN BODIES}

Seventy per cent of the foreign bodies were melon seeds and $15 \%$ were peanuts, shells of various nuts, and almond kernels. The rest $(15 \%)$ were screws ( 9 cases), metal pins (6 cases), fish bones (4 cases), a rosary bead, metal clips ( 2 cases), an ear-ring, a pebble, a nail cutter, and a metal toy (Fig. 5).

\section{MANAGEMENT OF ASPIRATED FOREIGN BODIES}

The course of the illness after inhalation of the foreign body and its management depend on the 


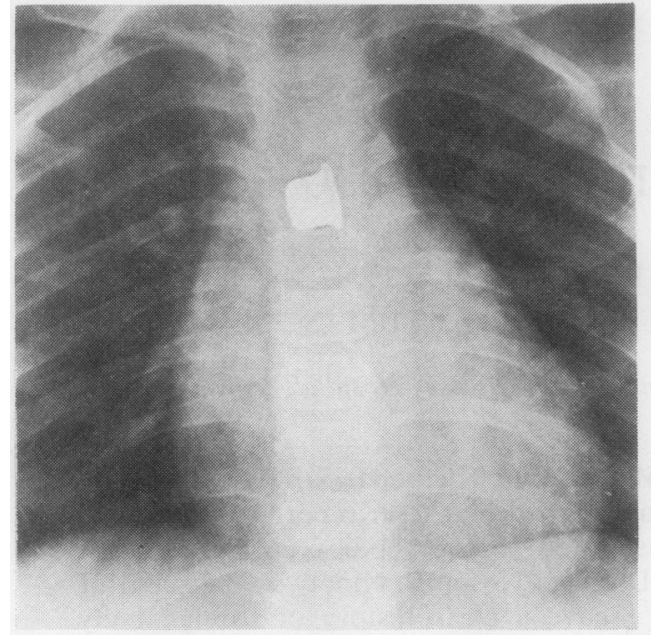

(a)

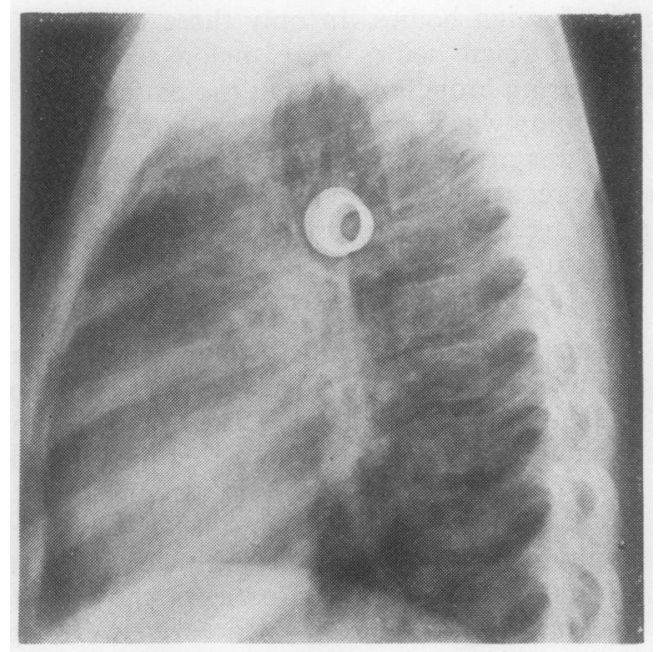

(b)

FIG. 1(a,b). Chest radiographs showing foreign body (whistle) just above carina.

patient's age, the position of the foreign body in the tracheobronchial tree, the duration of stay of this object in the air passages, and the nature of the foreign body. In our experience, over the last 14 years it has been possible to remove the foreign bodies in 247 cases by bronchoscopy under general anaesthesia, using for induction either thiopentone sodium $2.5 \%$ or inhalational anaesthesia with nitrous oxide, oxygen, and halothane followed by

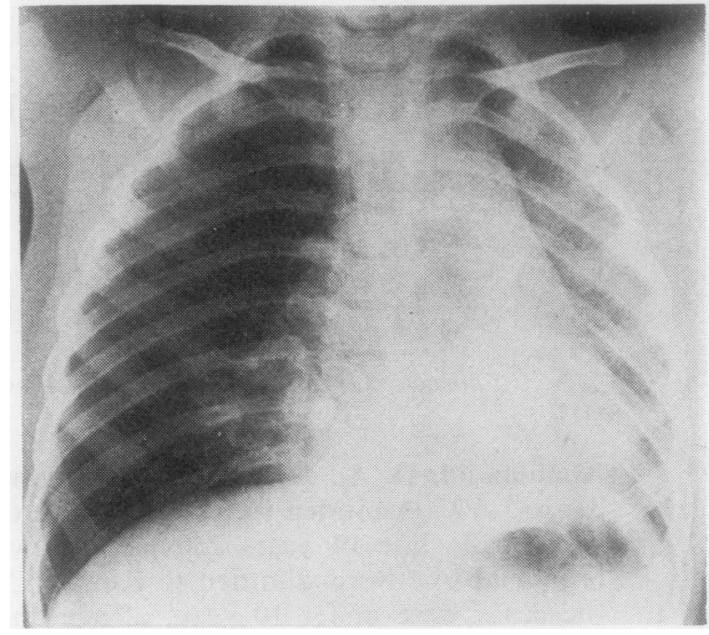

FIG. 2. Chest radiograph showing emphysema of right lung due to foreign body in right main bronchus.

succinylcholine and maintenance with inhalational anaesthesia.

Our successful results with bronchoscopy are attributable to two factors. First, the majority of foreign bodies were melon seeds which were relatively easy to remove at bronchoscopy. Secondly, the majority of patients were bronchoscoped soon after inhalation of the foreign body and before secondary inflammatory changes had developed in the bronchial tree. In three cases only did bronchoscopic removal fail. Two of these had screws penetrating the wall of the right bronchus, and in the third case there was a rosary bead impacted in the posterior segmental opening of the right lower lobe bronchus. In these three cases thoracotomy was done and the foreign bodies were removed through bronchotomy (Salomon, Shindel, and Levy, 1968).

\section{COMPLICATIONS OF ASPIRATED FOREIGN BODIES IMMEDIATE COMPLICATIONS}

1. Asphyxia and cardiac arrest occurred in four of our 250 patients. Management of such cases consisted of external cardiac massage and endotracheal intubation followed by thorough oxygenation. All four were successfully resuscitated and the foreign bodies were removed.

2. Severe obstructive dyspnoea occurred in 10 cases. Such a complication needed an urgent tracheostomy. 


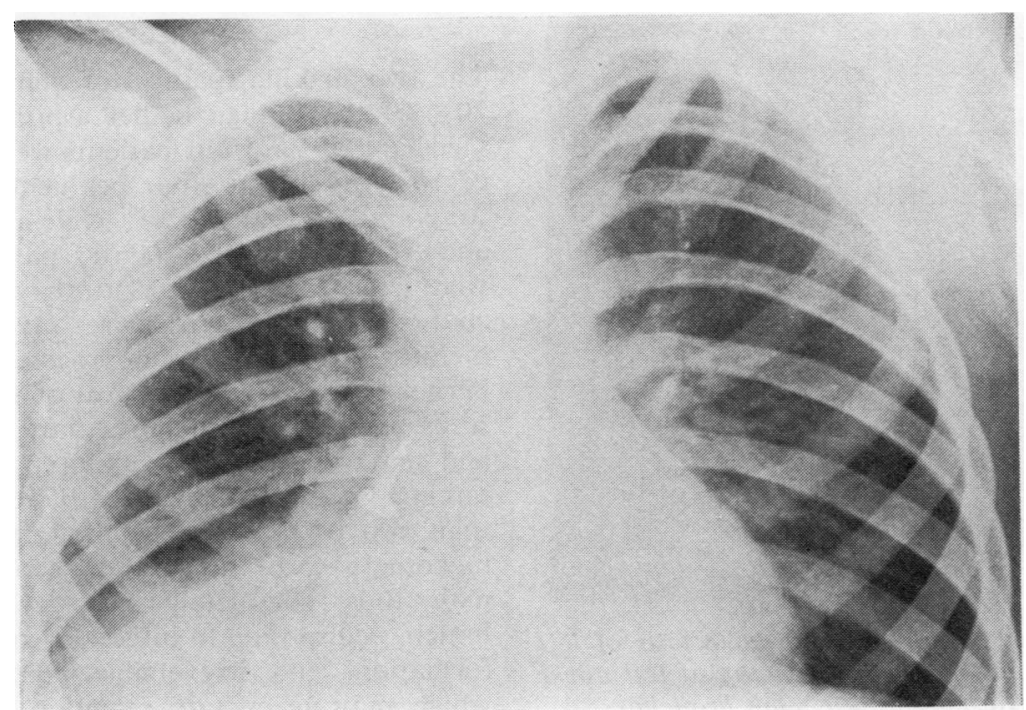

(a)

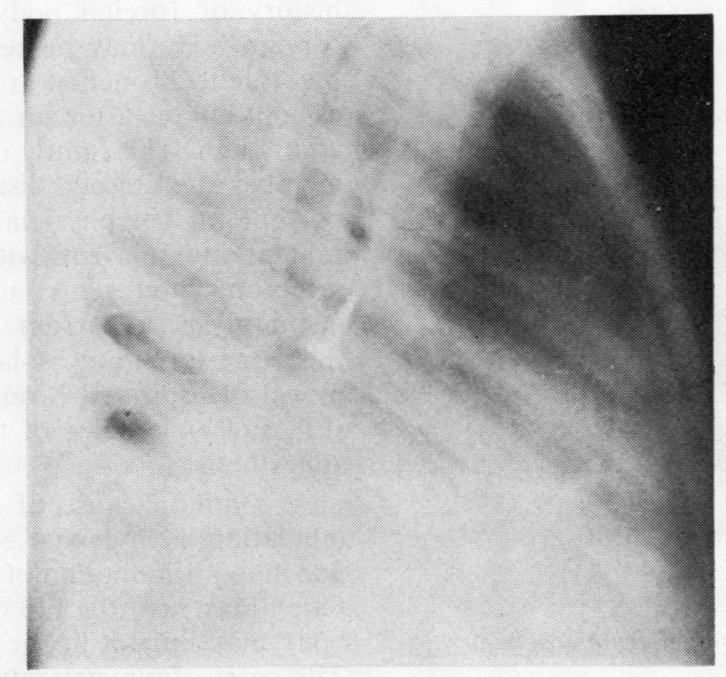

(b)

FIG. $3(a, b)$. Chest radiographs showing nail in right bronchus with collapse of right lower lobe.

3. Complications of bronchoscopy

(a) Trauma to the glottis: five patients developed severe respiratory distress shortly after bronchoscopy and successful removal of the foreign body. In spite of cortisone therapy after bronchoscopy a tracheostomy was necessary. (b) A right tension pneumothorax occurred in one patient after removal of the foreign body. This was due to injury of the right main bronchus and it was suspected from deepening cyanosis not responding to oxygenation. The diagnosis was confirmed by a chest radiograph. A 


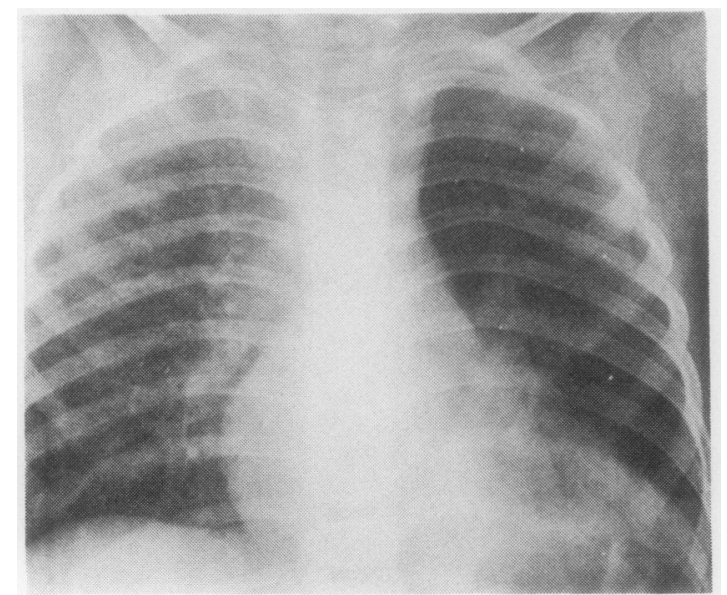

FIG. 4. Chest radiograph showing atelectasis of left lower lobe with obstructive emphysema of left upper lobe due to foreign body in left main bronchus.

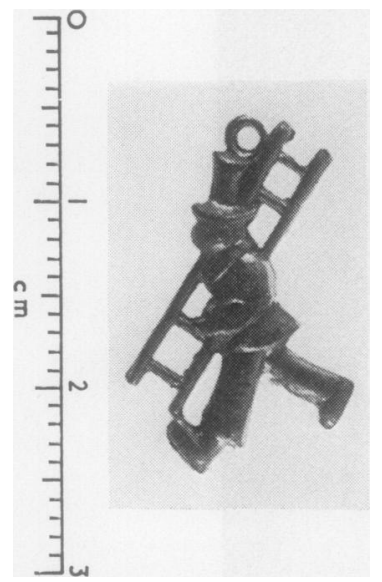

FIG. 5. Metal toy removed from trachea.

pleural drain was immediately inserted and the bronchial leak was closed by open thoracotomy.

LATE COMPlications In 15 patients late complications developed owing to retention of the foreign body in the bronchial tree for a few weeks or more. This gave rise to recurrent pneumonia in 12 cases (Fig. 6), lung abscess in one case, and cystic bronchiectasis in two cases (Deney et al., 1968).

\section{DISCUSSION}

The two striking features of our series were that $70 \%$ of the foreign bodies aspirated were melon seeds and $96 \%$ of our patients were under the age of 10 years. Eighty-four per cent of the patients were under 6 years of age, while among Johansson and William-Olsson's (1961) patients only $44 \%$ were less than 6 years old. In the majority of Arab countries melon seeds are saved from water melons, dried, salted, and roasted, and then the kernel is eaten after removal of the shell. As the seeds are mixed with saliva they become slippery and may be inhaled by children while crying or talking. A salted melon seed, if retained for more than two to three weeks, irritates the bronchial mucosa, absorbs fluid, and becomes swollen. It may thus completely obstruct the bronchial lumen, pedisposing to infection, granulation tissue formation, and irreversible pulmonary change, which may necessitate resection of one or more lobes. Only $38 \%$ of the patients gave a clear history of foreign body inhalation. However, a foreign body may be retained for a long time in the tracheobronchial tree, the patient remaining asymptomatic after an acute episode of choking and cough. The family or the patient may not remember the episode distinctly. It is therefore important for the physician to suspect foreign body inhalation in patients with unexplained pulmonary symptoms and signs such as unilateral wheeze, haemoptysis, recurrent pneumonia occurring in the same lung, and isolated lung abscess. The removal of aspirated foreign bodies depends on the skill and experience of the chest surgeon and the anaesthetist.

A common cause of death after foreign body inhalation is hypoxia, so preoxygenation, quick and smooth induction of anaesthesia, and laryngoscopy may save the life of the patient as a foreign body may impact in the subglottic region. Of our 250 cases, four patients had cardiac arrest due to severe hypoxia during the bronchoscopy procedure. They were successfully resuscitated and the foreign body was subsequently removed. Since early detection of cardiac arrest is essential, the use of a cardioscope before induction of anaesthesia is helpful. Bronchoscopy, when performed by a competent specialist, is usually a safe procedure, especially if the proper instruments are available and checked carefully before use. To avoid subglottic oedema cortisone was given immediately after bronchoscopy and for the following two days to all the patients under 2 years of age. Bronchoscopy may fail to remove some 


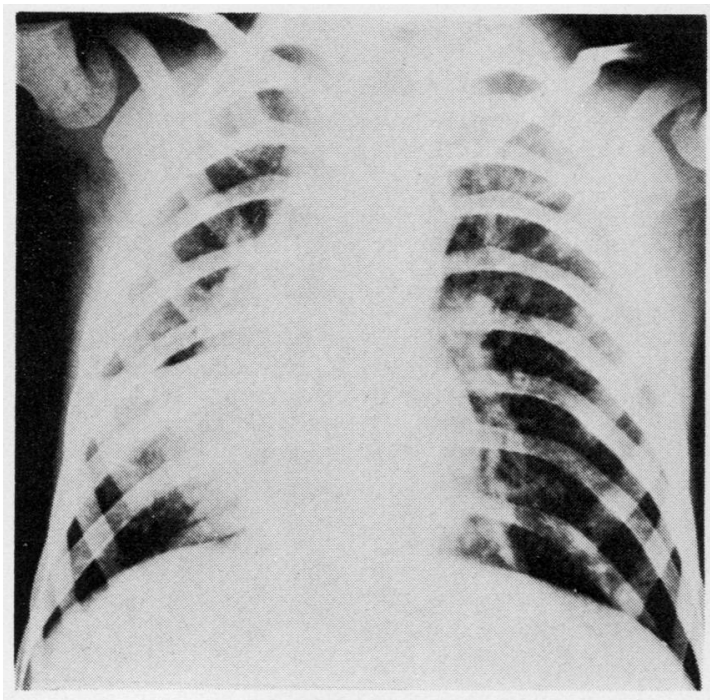

(a)

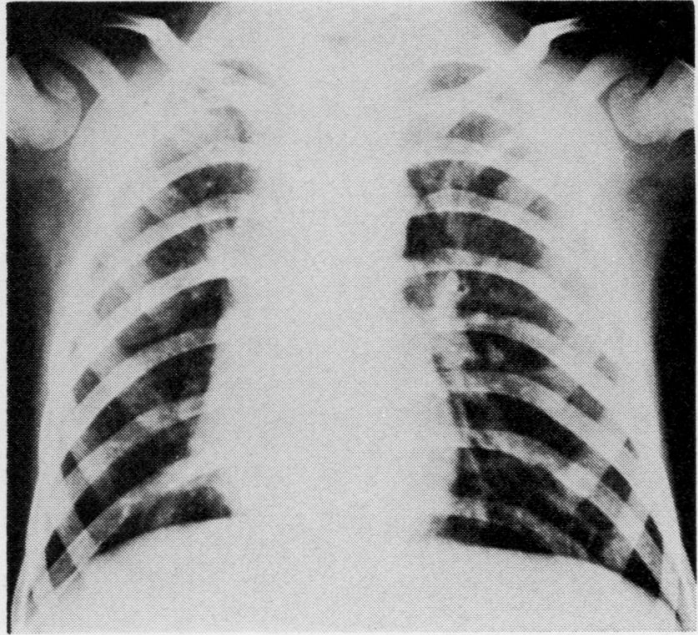

(b)

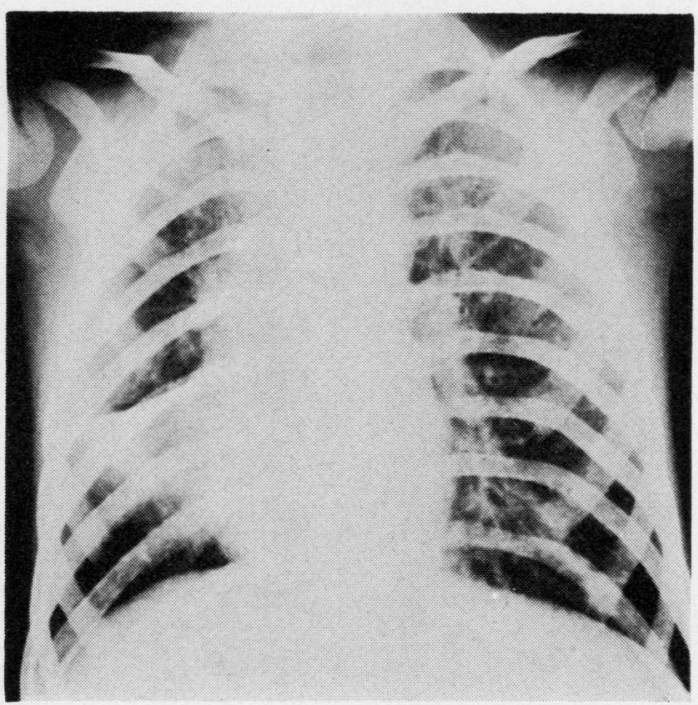

(c)

FIG. $6(a, b, c)$ Chest radiographs showing (a) pneumonia of right middle lobe due to undiagnosed foreign body in right main bronchus, (b) clearance, and $(c)$ recurrence.

foreign bodies, such as a screw or nail penetrating the wall of the bronchus, thus necessitating thoracotomy and bronchotomy. If bronchoscopy fails, it should be repeated after short intervals of physiotherapy and antibiotic treatment, and re- moval of the foreign body is usually possible. Cotton et al. (1973) suggested removal of foreign bodies by inhalational therapy and postural drainage, which may need up to 70 treatments. This may take up to seven days. We are more in 
favour of the use of bronchoscopy for the removal of foreign bodies. It is safer, much more rapid, and gives the opportunity to visualize the bronchial tree.

\section{REFERENCES}

Cotton. E. K., Abrams, G., Vanhoutte, J., and Burrington, J. (1973). Removal of aspirated foreign bodies by inhalation and postural drainage: survey of 24 cases. Journal of Clinical Paediatrics, 12,270
Deney, M. K., Berkas, E. M., Snider, T. H., and Nedwicki, E. G. (1968). Foreign body bronchiectasis. Diseases of the Chest, 53, 613.

Johansson, L. and William-Olsson, G. (1961). Foreign bodies in the bronchi. Acta Chirurgica Scandinavica, Supplement, 283, 153.

Salomon, J. S., Shindel, J., and Levy, M. J. (1968). Bronchotomy for removal of aspirated foreign bodies. Diseases of the Chest, 54, 39.

Requests for reprints to: Osama A. Abdulmajid, FRCS, Head of Thoracic Surgical Unit, Chest Diseases Hospital, Post Box No. 4082, Kuwait. 